\title{
Hollow-fiber Bioreactors: Present and Future in the Biotechnology Industry
}

José M. Vicaria*

Department of Chemical Engineering, Faculty of Sciences, University of Granada, 18071 Granada, Spain

The hollow-fiber membrane systems have been used as bioreactors years ago due to the advantages that present, such as, including two operations, reaction and separation, in the same system; these bioreactors can be used in batch, semi continuous or continuous processes, in biphasic or multi-enzyme reactions, showing high surface area in a small volume. The behavior of these membrane reactors (kinetic, fluid dynamics, modeling) has been studied in the past 30 years. They have been widely used in water purification, as dialyzers for removing low molecular weight species.

In the biotechnology and pharmaceutical industries this membrane configuration has been used with different enzymatic reactions (using lipases, proteases, hydrolases and cellulases), and cells cultures to obtain different products or to produce secreted proteins and antibodies from mammalian cells. The enzymes or cells are located on the membrane, or are confined in the lumen or in the extracapillary space. A suitable selection of the membrane material, flow and molecular weight cut-off allows that the enzymatic reactions or cells cultures evolve correctly, and that the exchange of substrate or products through the membrane was optimal.

In recent years, the use of these membrane bioreactors is growing, since they enable the separation of extracellular products from the cells, and it is possible perform a simple scaling using several units in parallel form, obtaining high productivities. Hollow-fiber cell cultures present advantages versus classic suspension cultures because cells are bound to a porous matrix much, as they are in vivo, and they are cultured in a per fused environment without shearing. Also, high-density cell cultures can be achieved, allowing significant reductions in cell culture media and other additives

Some of the present and future uses of the hollow-fiber bioreactor are cultures of endothelial cell and hepatocyte, recombinant protein production or monoclonal antibodies, lymphocyte culture, culture of placental derived cells, or production of viruses in vaccine manufacturing. Hollow-fiber bioreactors offer a compact, highly efficient, scalable and economical method for virus production. The concept of "scaling out" by using multiple small reactors, with each reactor designated to provide a patient-specific treatment, instead of "scaling up" to a single large bioreactor system is gaining popularity.

Another application is its use for "In vitro Toxicology" to model pharmacologic bio-availability for different antimicrobial drugs, and also to simulate dosage profiles that generate resistant organisms. Anticancer agents, anti-fungals, antibiotics, anti-virals (including anti-HIV) and anti-parasitic drugs have been tested in hollow fiber bioreactors.

*Corresponding author: José M. Vicaria, Department of Chemical Engineering, Faculty of Sciences, University of Granada, 18071 Granada, Spain, E-mail: vicaria@ugr.es

Received September 04, 2013; Accepted September 13, 2013; Published September 16, 2013

Citation: Vicaria JM (2013) Hollow-fiber Bioreactors: Present and Future in the Biotechnology Industry. J Membra Sci Technol 3: e118. doi:10.4172/21559589.1000e118

Copyright: (c) 2013 Vicaria JM. This is an open-access article distributed under the terms of the Creative Commons Attribution License, which permits unrestricted use, distribution, and reproduction in any medium, provided the original author and source are credited. 